\title{
DATOS PARA LA HISTORIA ARQUITECTÓNICA Y URBANÍSTICA DEL COLEGIO E IGLESIA DE LA COMPAÑÍA DE JESÚS EN JEREZ DE LA FRONTERA Y SU POSIBLE AUTORÍA (1598-1704)
}

\section{Esperanza de los RIOS MARTINEZ \\ Facultad de Bellas Artes (Sevilla)}

\section{RESUMEN}

Estudio de la Iglesia jesuita de Jerez de la Frontera.

Palabras clave: Historia del Arte. España. Arquitectura. Siglo XVII. Jerez de la Frontera.

\section{$\underline{\text { SUMMARY }}$}

Analysis of the jesuit church of Jerez de la Frontera.

Keywords: Art History. Spain. Architecture. XVIIth century. Jerez de la Frontera.

Del Colegio de la Compañía de Jesús en Jerez nos han llegado la iglesia, en un total estado de ruina y abandono y parte de un pórtico de arcos, situado en el costado del Evangelio del templo. Reutilizados estos elementos en un edificios de viviendas, han sido bastante deformados, aunque aún se puede preciar la concepción del proyecto original.

Según el historiador Francisco de Mesa Ginete, los Jesuitas se instalaron en la ciudad en 1574, cuando el Cabildo de la Ciudad, ante las necesidades docentes cada vez más acuciantes, solicitaron al Consejo Real que se fundase un Colegio de la Compañía; el Rey concedió la fundación en 1580, asignando unas rentas para su mantenimiento ${ }^{1}$.

La necesidad de un centro de enseñanza de calidad se debía a que las antiguas Cátedras de Humanidades y Latinidad de los conventos de San Francisco y Santo Domingo se habían quedado desatendidas, al incorporarse a la Observancia estas Ordenes.

Tras deambular por diversos emplazamientos los jesuitas se encontraban en 1603 asentados en el lugar que, hasta el presente, ha conservado el nombre de "Plaza de la Compañía", donde permanecieron hasta mediados del siglo XX. Desde su edificación la iglesia estuvo bajo la advocación de "Santa Ana de los Mártires", haciéndose así referencia a la leyenda de los Mártires de Asta ${ }^{2}$. 
La problemática urbanística suscitada por esta fundación se suscitó de forma casi inmediata, debida la lucha por el espacio para ampliar sus dependencias que caracterizó al urbanismo jerezano de estos años. En un principio, el Ayuntamiento les había donado, para su uso particular, una callejuela que atravesaba el convento y que nunca llegó a plantear problemas. Sin embargo, no ocurrió lo mismo con otro callejón que recorría la trasera de las instalaciones jesuíticas y cuyo trayecto final conducía al vecino convento de monjas Mínimas de San Francisco de Paula; cuando este pasaje le fue concedido también a la institución masculina, las monjas no pudieron menos que rebelarse, considerando que ellas tenían el mismo derecho a obtener este espacio para ensanchar sus instalaciones.

En 1612 los jesuitas estaban construyendo su colegio, así como las habitaciones destinadas a los religiosos; estas obras fueron el detonante para que la congregación femenina se alzara indignada ante la invasión del callejón fronterizo y el deseo de incorporarlo, ellas también, a su entorno.

La polémica fue llevada al Ayuntamiento para que sirviese como árbitro aunque había sido, en gran parte, el causante del enfrentamiento. Así pues, el día 27 de Marzo de 1612 Juan Pérez de Aguilar, Rector de la Compañía, comparecía ante los caballeros veinticuatro para justificar su necesidad imperiosa de anexionarse el exiguo pasadizo. Sus argumentos se centraban en el hecho de que estaba edificando unas habitaciones y que el incorporar a éstas "una calleja muy angosta" haría que las estancias fuesen más cómodas.

Sin embargo, las religiosas no se habían quedado indefensas, pues en su nombre acudió el Rector del Colegio de la Victoria, Fray Fernando de Guzmán, quien estaba lejos de consentir lo que sus defendidas consideraban un total avasallamiento, argumentando que también para las religiosas tenía utilidad aquel espacio por reducido que fuera ${ }^{3}$.

Sin embargo, la importancia de las instituciones masculinas era muy superior a la de las femeninas en el Jerez del Antiguo Régimen y la vía pública fue adjudicada a los jesuitas.

El resultado no complació ni a los Mínimos ni a una gran parte del Cabildo, a causa de los patronazgos y devociones existentes de una y otra parte y a las relaciones familiares de unos y otros. La discordia fue tan intensa y la imposibilidad de poner de acuerdo a los jueces se convirtió en tarea de titanes por lo cual los caballeros veinticuatro en lo único que estuvieron de acuerdo fue en recurrir a la Corte enviando un memorial donde daban su versión de los hechos.

Los argumentos se centraban en que la vía era un lugar peligroso y sucio, susceptible de que en él se cometiesen toda clase de atropellos y 
robos, motivo por el cual al Ayuntamiento no les resultaba útil, mientras que a la Compañía les sería beneficioso incorporla a su edificio, con lo cual se eliminaría un foco de riesgos. La Corte respondió con una cédula, fechada el 27 de Febrero de 1613 en tales términos que no hizo sino alborotar más los ánimos de los implicados ${ }^{4}$.

La propuesta consistía en entregarles a los padres la zona en litigio pero éstos, como compensación, debían entregar para uso público una vara de ancho de una calle principal que discurría por delante de su iglesia, con lo cual el Cabildo recuperaría el uso de una vía más importante que la del anterior litigio. Inmediatamente se aceptó el trato por ambas partes, aunque sin contar con los terceros en discordia: el General de los Mínimos se reveló nuevamente ante la decisión.

Alegaba en esta ocasión que la calle propuesta para el intercambio conducía directamente a la portería de las religiosas con lo cual se les impediría el libre uso de ésta. Del uso de dicha calle habían disfrutado las monjas desde su llegada a la ciudad, un siglo antes que los jesuitas. Buscando una posibilidad de llegar a un acuerdo o, mejor aún, un truco que impidiese a la Compañía conseguir sús propósitos, el General de los Mínimos sugería que se otorgase parte del pasadizo pero dejando un espacio de diez pies de ancho para preservar el acceso de las monjas a la portería y al torno, lugares de uso común; de igual manera, los padres debían comprometerse a dejar libres los muros del edificio que lindaban con ellas.

La argucia consistía en que la calle solamente tenía una anchura de siete pies, lo cual evidenciaba la imposibilidad de llevar el posible trato a la realidad: la calle era, prácticamente, indivisible. De esta manera, el acuerdo no se resolvió nunca, y prosiguió la diatriba hasta que murió por verdadero desinterés, cuando finalizaba el siglo XVII ${ }^{5}$.

Estos pleitos promovidos por las ordenes religiosas con la finalidad de aumentar el espacio disponible de sus recintos, fue una de las características del urbanismo del Antiguo Régimen pues los cascos urbanos de las ciudades, saturados de iglesias y conventos, no daban a éstos más posibilidades de expansión que las de anexionarse espacios públicos poco frecuentados, bajo el habitual pretexto de que se transformaban en punto de encuentro de maleantes y prostitutas. Antonio Bonet Correa interpreta esta actitud seiscentista dándole un matíz más intelectual: considera que la ciudad convento así generada, pretendía reconstruir, a escala humana, el modelo del Templo de Salomón, transformando, de esta manera, la ciudad en una "Jerusalén Terrestre"; precisamente fueron los tratadistas Prado y Villalpando, ambos jesuitas, los propugnadores de esta última idea ${ }^{6}$.

Sin embargo, retomando el hilo principal de este trabajo, nos detendremos ahora en explicar la actuación arquitectónica que, durante este 
tiempo, no habían dejado de llevar a cabo los jesuitas y que explica la constante necesidad de espacio para poder edificar y luego ampliar sus dependencias.

Las trazas del Colegio que desde 1612 se estaban llevando a cabo, pudieron deberse al arquitecto de la Orden, el Hermano Pedro Sánchez. Las obras debieron realizarse sin demoras pues en 1631 el Colegio no solo estaba ya a pleno rendimiento, sino que además se habían quedado pequeñas las clases dado el gran numero de alumnos que acogía.

Así pues, según la tónica habitual entre las congregaciones religiosas de la época, les fue preciso acudir nuevamente al Ayuntamiento para solicitar más espacio y ayuda económica para ampliar dichas dependencias que, además, amenazaban ruina ${ }^{7}$.

Acudió personalmente el Rector para explicar a los caballeros veinticuatro que tenían necesidad de levantar más aulas en sus escuelas pero al no disponer de fondos suficientes solicitaban una limosna de mil ducados; estos fondos podrían obtenerse del arrendamiento de una Dehesa llamada "del Hato de la Carne" y que pertenecía a los Bienes Propios de la ciudad.

Como esta dehesa daba grandes beneficios, sugerían que la cantidad que excediese de la solicitada les fuese entregada también, para los imprevistos que pudieran presentarse. Como reconocimiento a la ayuda municipal se ofrecían, según práctica habitual de los religiosos de la época, a hacer la construcción con el mayor ornato posible conmemorando así que fue la Ciudad quien hizo la limosna. Votada la petición y teniendo en cuenta la utilidad de la enseñanza impartida a los jóvenes, acordaron entregar 500 ducados de los Bienes de Propios para efectuar las mejoras propuestas.

A pesar de tantas quejas y lamentaciones, la situación de ésto no debía ser, ni mucho menos, tan deplorable, o, al menos, supieron invertir muy bien la limosna del cabildo pues en 1636 la Orden compraba una casa y un establo de bueyes en las Atarazanas (hoy Plaza de San Andrés), junto al Convento de Santo Domingo; testigos de la compra fueron el maestro albañil Sebastian Jiménez y el carpintero Andrés del Valle, ambos profesionales muy activos en Jerez durante la primera mitad del siglo XVII y que, posiblemente, pudieron intervenir en las empresas constructivas de la Compañía ${ }^{8}$.

Estas casas pudieron ser entregadas a censo para que su arrendamiento ayudase a sostener los constantes gastos de mantenimiento del Colegio y, naturalmente, en las construcciones que se le iban añadiendo. 
Además, siempre se presentaban imprevistos que complicaban los presupuestos iniciales. Uno de éstos fue el terremoto que en 1636 causó la ruina de muchos edificios históricos de Jerez. Como consecuencia, aunque un tanto tardía, del seismo, el Colegio también se resintió, pero hasta 1638 no acudió el Rector, Juan de Cuadros, a solicitar las consabidas limosnas municipales. En esta ocasión había sido el aula donde se impartían las clases de gramática la que se había resentido de tal manera que se temía su desplome; además, por estar situada en el interior de la clausura la habían dejado incomunicada ${ }^{9}$.

Para compensar el daño y de forma provisional, mientras que se hacían las reparaciones pertinentes, solicitaban que les permitiesen dar las clases en la vecina capilla de la Pura y Limpia Concepción ${ }^{10}$, dejando claro que con este préstamo de espacio no intentaban adquirir derecho alguno sobre la capilla y, mucho menos, adueñarse de ella; como precedentes en casos similares citaban que en tiempos pasados se leía en ella la lección de Artes. Este lugar podría servir, así mismó, para decir misa a los alumnos, ya que el Colegio aún carecía de una iglesia propia.

Aún así, sería preciso hacer algunas obras en el aula provisional, al parecer, también en condiciones precarias, contando con la ayuda municipal tanto para restaurar la capilla solicitada como el aula clausurada; el Ayuntamiento accedió a todas las peticiones y se realizaron sin tardanza las mencionadas restauraciones.

Tardaron varios años en edificar la iglesia, pues esta era una empresa que requería tiempo y dinero; cuando los fondos estuvieron reunidos se comenzó a sacar de cimientos en la fecha de 19 de Septiembre de 1669 y se terminó la capilla mayor el 20 de Febreró de $1672^{11}$.

No sabemos, con exactitud, si de este primer templo se ha conservado algo reutilizado en el que ha llegado hasta nuestros días, puesto que en el año de 1679 un incendio la arrasó, según los documentos, por completo, si bien siempre nos queda una duda razonable acerca de la posibilidad de que alguna parte haya sobrevivido a este desastre.

La noche del 21 de Diciembre del mencionado año se declaró un violento incendio en la sacristía y de allí pasó a la iglesia, devastando altares, ornamentos e imágenes, con tal rapidez y voracidad que a duras penas se pudo rescatar el Santísimo, aunque poniendo en riesgo la vida de quien se atrevió a ello. Junto con la iglesia ardieron dos aulas, la ropería de los curas y el dormitorio de éstos. Para evitar daños aún mayores y que no ardiese la casa al completo fue preciso atajar el fuego demoliendo una parte del edificio ${ }^{12}$.

Tras el relato del grave accidente en el Ayuntamiento, los caballeros veinticuatro consideraron prioritario la reedificación de la iglesia y la parte 
del colegio destruida. El templo resultaba fundamental para el vecindario que acudía a él para confesar y oir explicar la Doctrina Cristiana, especialmente en los días de Cuaresma; así mismo, estos sacerdotes solían recorrer el amplio término municipal de Jerez, llevando sus enseñanzas a lugares muy alejados de cualquier centro religioso y abandonados por las demás congregaciones de la ciudad, más acomodaticias y menos aventureras que los jesuitas.

La consecuencia fue la de solicitar al Rey una facultad para que les destinase la cantidad de 4.000 ducados procedentes de los arbitrios destinados a las Obras Públicas de la ciudad, entre ellas, la traída de aguas desde Montealegre hasta la Alcubilla, pues consideraban más importante este asunto que el mantener en buen uso la infraestructura de la ciudad, ya de por sí deficitaria.

La Compañía de Jesús, sin embargo, tropezó en esta ocasión con un escollo más difícil de sortear que los anteriores. Se trataba de que también era preciso reedificar la Colegiata de la ciudad, arruinada a causa de un terremoto ocurrido en el mes de Julio del mismo año.

De nuevo un largo pleito se inició, esta vez entre los jesuitas y el Cabildo de la Colegiata que, por ser fundación real tenía preferencia. En el año de 1690 el Consejo Real le negaba los fondos solicitados pero el Ayuntamiento, acuciado por la falta de una enseñanza de calidad, concedió, una vez más, dineros de sus Bienes de Propios; así fue terminada la iglesia $y$ consagrada en $1704^{13}$.

El templo se había comenzado en 1696 y en un memorial enviado en 1698 se solicitaban los 4.000 ducados ofrecidos por el Ayuntamiento y que aún no habían recibido (15).

En otro memorial de 1699 se daba cuenta del estado de las obras ya realizadas. En esa fecha ya estaban terminados los arcos, bóvedas y cornisas siendo, sin embargo, necesarios otros mil ducados para terminar el enlucido del interior y terminar el conjunto de la decoración; la comunidad añadía que si de los mil ducados sobraba alguna cantidad, podrían emplearla en labrar blasones y puertas para completarla; por supuesto que los ducados fueron concedidos sin demora ${ }^{14}$.

Comentamos, a continuación, las características formales del conjunto arquitectónico que ha llegado hasta nuestros días.

La iglesia está edificada enteramente de cantería y en ésto, como en sus demás aspectos constructivos, en gran medida arcaizantes y relacionados con la tradición goticista de los constructores de la ciudad, muy revitalizada en estos años finales del siglo XVII, responde a unas 
características generalizadas en la arquitectura religiosa jerezana de su época.

Es de planta rectangular, con tres naves y crucero que no se acusa en planta; el presbiterio fue reformado en época contemporánea para dotarlo de un camarín.

Sobre las naves laterales se abre una serie de balcones practicables para asistir a las funciones de la nave principal, de forma similar a otras iglesias conventuales que se estaban terminando en Jerez en estos mismos años, como es la del Carmen.

La cubierta de la nave central era de bóveda de medio cañón con lunetos y retalles para contener lienzos, si bien en la actualidad está derrumbada casi por completo.

Las naves laterales son sensiblemente más bajas que la central, lo cual le confiere un acentuado rasgo de arcaísmo; se cubre con bóveda de crucería con arcos fajones de gran anchura. Los muros, así mismo de gran espesor, albergaban los desaparecidos retablos en arcos rehundidos ${ }^{15}$.

En los testeros de los colaterales sendas puertas conducen a la sacristía y dependencias anexas. Los vanos son adintelados, enmarcados por pilastras almohadilladas y rematadas por frontones triangulares ornamentados por emblemas mariológicos.

Respecto a la planta de este templo, podemos observar que, siendo muy funcional para albergar el mayor número de fieles y respondiendo a la traza de la iglesia conventual de tradición medieval, no guarda relación alguna con la estructura de la iglesia jesuítica divulgada a partir del "Gesú" de Roma. Muy por el contrario, hunde sus raíces en las estructuras medievales omnipresentes en Jerez y así lo muestran sus bóvedas de crucería de las naves laterales, reforzadas por arcos fajones e idénticas a las que se conservan en la Colegiata, hoy Catedral, de la ciudad:

Los pilares de la nave central están decorados con series ininterrumpidas de círculos entrelazados que componen una flor esquemática en el centro; en los colaterales los motivos alternan cuadrados concéntricos con círculos entrelazados que, a pesar de la tosquedad y planitud de su ejecución pueden estar inspirados en algunos modelos de los Libros Tercero y Cuarto de Serlio, concretamente en los mosaicos del Templo de Baco ${ }^{16}$.

En líneas generales estos motivos recuerdan a los empleados por Antón Martín Calafate durante la primera mitad del siglo y continuados, al parecer, por los canteros jerezanos, mediante la transmisión de unos a otros de las plantillas para realizar estas tallas. 
La portada principal de la iglesia está situada a los pies de la nave central; está formada por un solo cuerpo y al parecer, está incompleta pues su estructura revela el inicio de un segundo piso, no sabemos si esbozado e interrumpido o desmontado tras su finalización; en el centro se conserva un rosetón de tracería hoy cegado. Su configuración se inspira fielmente en el primero de la torre fachada de la Parroquia de San Miguel, en la misma ciudad; dicha torre es la obra más conocida y al mismo tiempo criticada, de su autor, el arquitecto jerezano Diego Moreno Meléndez.

Se abre con un vano adintelado encuadrado por un baquetón mixtilíneo, coronado por un tímpano de dovelaje despiezado; el conjunto queda flanqueado por pilastras almohadilladas, rematadas por capiteles ménsulas y columnas dóricas de fuste tallado con motivos vegetales estilizados, idénticos a los de su indudable modelo. Los elementos de cardinas planas que se aprecian en las enjutas, así como los motivos florales de las metopas y del baquetón quebrado muestran un seguidor fiel de Diego Moreno Meléndez.

Sin embargo, a pesar de la evidente relación formal entre ambas obras, no podemos certificar que sean contemporáneas o realización directa del mismo arquitecto; la falta de documentación al respecto unida a las óptimas condiciones de su conservación que la han hecho permanecer casi indemne a los cambios climatológicos y a la intervención humana, hacen pensar en un seguidor del mencionado arquitecto jerezano que incluso pudiese haber trabajado sobre unas trazas previamente dadas por aquél, si bien, de realización en una época más tardía.

En cuanto al claustro, como dijimos conservado parcialmente adosado a la nave del Evangelio de la iglesia, pudo formar parte de la portería del Colegio.

Tras el derribo del edificio esta arquería fue parcialmente reutilizada en un edificio de viviendas contemporáneas de nueva planta. En su origen constaba de cuatro lados iguales, reducidos actualmente a dos lados de longitudes desiguales. Ambos lados forman un ángulo recto; en el que está adyacente al costado de la iglesia hay cuatro arcos y cinco en el contiguo. Los arcos, de medio punto, apean sobre columnas de mármol y orden toscano; la clave de éstos queda destacada por una ménsula. La cornisa, sobre modillones sostiene un entablamento con metopas lisas y triglifos.

En general, los colegios de la Compañía, por su distribución y organización de espacios, solían tener una evidente semejanza con los edificios conventuales. Habitualmente eran de planta cuadrada, con un patio en el centro y la capilla situada perpendicularmente al eje del edificio, bien en la fachada posterior o en una de las alas laterales de ésta. 
En la configuración de los centros de enseñanza jesuíticos el Hermano Pedro Sánchez tuvo la relevancia de ser quien configuró su estructura arquitectónica de forma práctica y armoniosa. La figura de este arquitecto ha sido estudiada y dada a conocer por Alfonso Rodríguez Gutiérrez de Ceballos ${ }^{17}$.

Sánchez era albañil cuando ingresó en la Compañía en 1591. Desde 1597, en la Casa Profesa de Sevilla, se le asignó el trabajo de "hacer trazas" y desde 1603 se encontraba inmerso en el estudio de los libros de Vitrubio, Serlio y Vignola. Desde esta fecha se dedicó plenamente a su tarea profesional, desplazándose por toda Andalucía, dirigiendo la construcción de las casas de su Orden entre los años de 1600 a 1630 . A esta tarea estuvo entregado hasta 1620, año de su muerte, ocurrida en Madrid cuando trazaba la planta del Colegio Imperial.

Como da a conocer la correspondencia con Roma, donde el Padre General debía aprobar todos estos proyectos, la idea fundamental que subyacía en estas instalaciones era la de atenerse al sentido práctico y a la utilidad, antes que la mera belleza formal.

En la Biblioteca Nacional de París se han conservado tres planos firmados por este arquitecto; sin embargo, no se puede decir lo mismo de los alzados correspondientes, pues los detalles relativos a éstos, así como sus medidas se adjuntan por escrito. De todas formas, sobre estos planos se ha podido datar con seguridad otros trabajos relacionados con el Hermano Sánchez.

El plano del Colegio de Écija data de 1607. Presenta un pequeño patio junto a la sacristía de la iglesia y detrás de ésta se ubicaba la escuela, distribuida en torno a otro patio porticado de mayores dimensiones. También existían otros dos patios menores destinados respectivamente a los seglares y a la comunidad; entre ambos mediaba la escalera principal ${ }^{18}$.

El de Guadix y el de Jerez están fechados en 1610 y guardan mayores similitudes. El de Guadix presentaba una portería abierta y porticada en un costado de la iglesia, de forma semejante a la disposición del de Jerez. Detrás se situaba el colegio en torno a un claustro, en uno en cuyos lados se disponían las oficinas y otro patio de servicio (20). Las similitudes entre ambos son evidentes, por lo cual, al menos en lo que a las trazas de la escuela no se plantean mayores dudas, permaneciendo abierta la incógnita de la autoría de la iglesia que, esperamos, puedan resolverse en breve. 


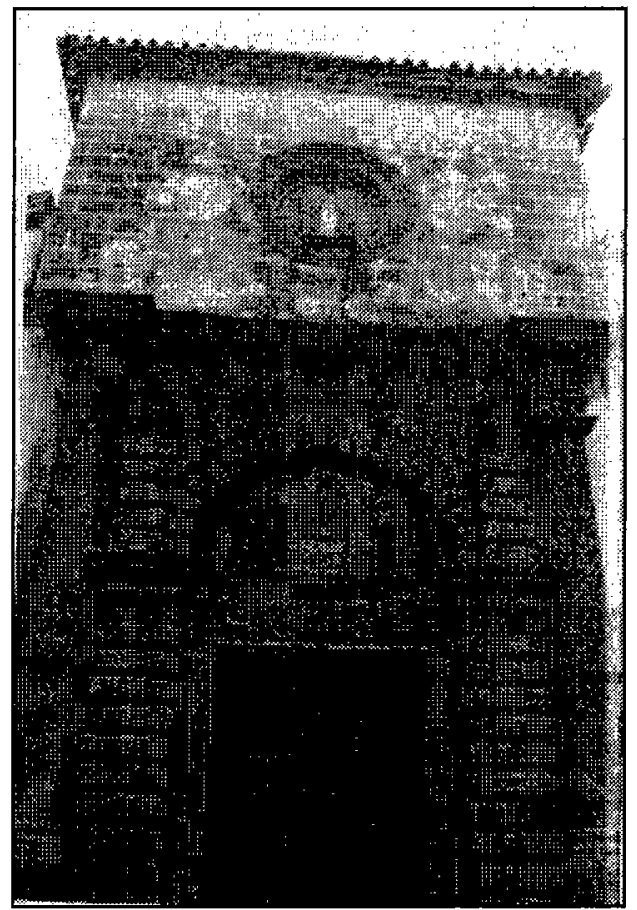

Jerez de la Frontera.

Compañía de Jesús.

Portada de la iglesia (16961704).

Círculo de Diego Moreno Meléndez

Jerez de la Frontera.

Compañia de Jesús.

Interior de la iglesia

(1696-1704).

Círculo de Diego Moreno

Meléndez

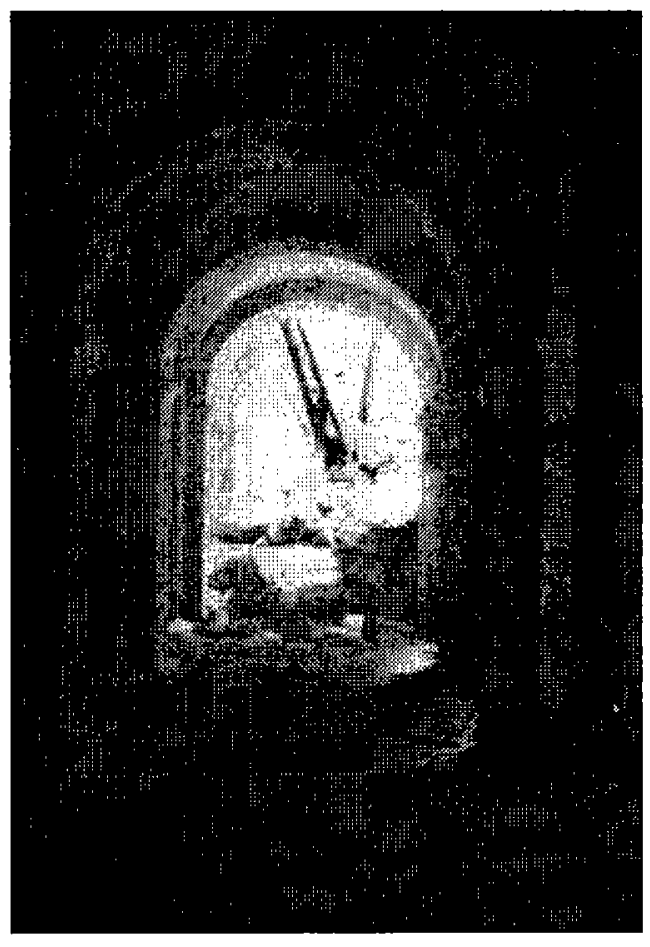


Jerez de la Frontera.

Compañia de Jesús.

Claustro de la Postería (circa 1610).

Hermano Pedro Sánchez

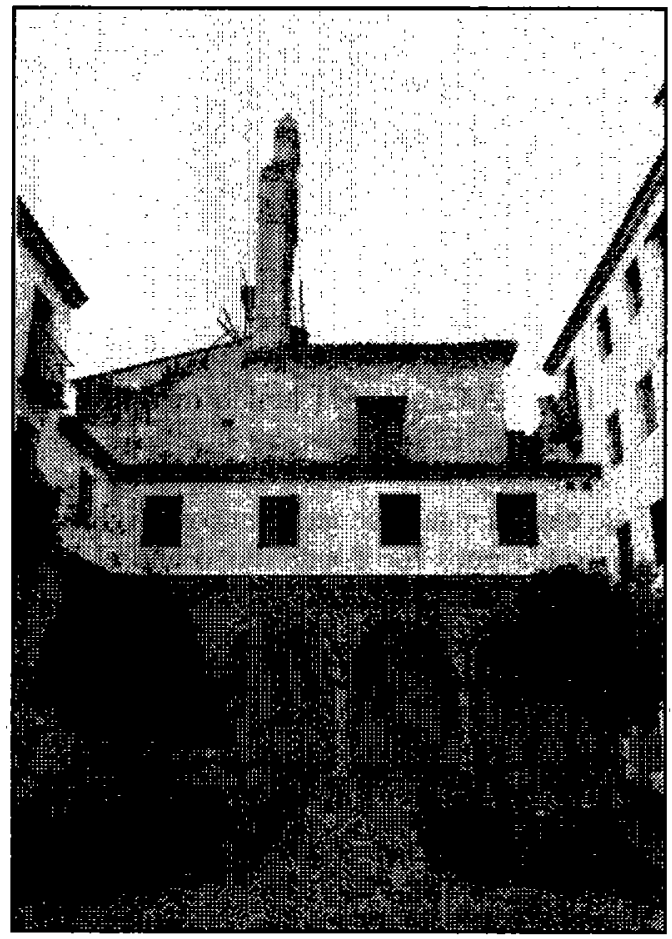

NOTAS:

1 Francisco de Mesa Ginete:Historia Sagrada y Política de...Jerez de la Frontera.- Jerez, Imprenta de Melchor García Ruiz, 1888. Hipólito Sancho de Sopranis: Establecimientos docentes de Jerez en la segunda mitad del siglo XVI.- Centro de Estudios Históricos Jerezanos, $\mathrm{n}^{\circ} 5$, Jerez, 1959; p.p. 55-63.

2 Mesa Ginete, op. cit. p.p.168-175. Relata detenidamente la leyenda de los Mártires de Asta, error difundido en los siglos XVII y XVIII y de la cual los jesuitas fueron los principales valedores.

3 Archivo Municipal de Jerez de la Frontera (A.M.J.F.) Actas Capitulares (A.C.) 1611-1612. Cabildo de 27 de Marzo de 1612; f $^{\circ}$ 1036 r. $-1037 \mathrm{vt}^{\circ}$.

4 A.M.J.F.; A.C. 1613-1614; Cabildo de 18 de Febrero de 1613, fo 372 $v t^{\circ}-374 \mathrm{r}$.

5 Ibidem. 
6 Antonio Bonet Correa: Fiesta, poder y arquitectura.- Madrid, Akal, 1990. El Urbanismo en España e Hispanoamérica.- Madrid, Cátedra, 1991.

7 A.M.J.F.; A.C. 1631, Cabildo de 31 de Mayo de 16331; $f^{\circ} 1148 \mathrm{vt}^{\circ}$.

8 Archivo de Protocolos Notariales de Jerez de la Frontera. Oficio 22, Pedro Camacho Grajales, 1636, T. 246, po 274-275.

9 A.M.J.F.; A.C. 1638, Cabildo de 12 de Julio de $1638, \mathrm{f}^{\mathrm{o}} 724 \mathrm{vt} \mathrm{t}^{\circ}-725$ $\mathrm{vt}^{\mathrm{o}}$.

10 Esta capilla estaba situada junto a la iglesia de San Marcos (...) en 1467 ya existía pues fue donde dicho año el Duque de Medina juntó a los caballeros de Jerez para poner fin, reconciliándose, a todas sus banderías. (Mesa Ginete, op. cit. p. 474).

11 Idem, p. 174.

12 A.M.J.F., A.C. 1679, Cabildo de 22 de Diciembre de 1679, fo $703 \mathrm{vt}^{\circ}$.

13 Mesa Ginete, op. cit. p. 174. A.M.J.F., A.C., 1692, Cabildo de 27 de Marzo de 1692, $\mathrm{f}^{\circ} 951 \mathrm{vt}^{\circ}$ y $952 \mathrm{r}$..

14 A.M.J.F., A.C. 1698, Cabildo de 23 de Octubre de 1689, fo 335.

15 Antonio Bonet Correa: La arquitectura en Galicia durante el siglo XVII.- Madrid, 1984; p. 56. Elie Lambert: El arte gótico en España.Madrid, 1982, p.p. 77-87. Fernando Chueca: Historia de la arquitectura española. Edad Antigua Edad Media.- Madrid, 1965, p. 289-230.

16 Sebastiano Serlio: Tercero y Cuarto Libro de Arquitectura.- Toledo, 1552 (Reedición Barcelona, 1990) Libro Tercero, Lám. XIII.

17 Alfonso Rodríguez Gutiérrez de Ceballos: El arquitecto hermano Pedro Sánchez, en: "Archivo Español de Arte", Madrid, 1970, T. XLIII; p.p. 51-81. J. Vallery-Radot: Le recueil de plans de la Compagnie de Jesus conservé a la Bibliotheque National de Paris.Roma, 1960.

18 Ibidem. 